\title{
Association between the choice of anesthesia method and reactivity to chemotherapy in children with acute lymphocytic leukemia: a preliminary retrospective cohort study
}

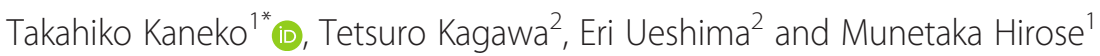

\section{To the Editor,}

Immune cell suppression by inhalation anesthetics can decrease patients' response to chemotherapy for leukemia, although only a few reports have examined this [1]. We investigated the relationship between general anesthesia methods (propofol and sevoflurane) for tunneled central venous catheter (tCVC) insertion in pediatric patients with precursor $B$ cell acute lymphocytic leukemia (BCP-ALL) and the residual leukemic blast cell count in peripheral blood on day 8 following prednisolone chemotherapy (day8 PB blast cell count), an indicator of response to treatment [2].

The subjects of this single-center retrospective cohort study were BCP-ALL patients aged less than 18 years who underwent tCVC insertion under general anesthesia. During the research period of January 2012 through October 2018, the same chemotherapy protocol was used as the primary treatment for pediatric BCP-ALL at our institution. The exclusion criteria decided beforehand were discontinuation of prednisolone chemotherapy, age less than 1 year and/or positive Philadelphia chromosome cases requiring different treatment methods
[2], and tCVC insertion after starting chemotherapy. The relationship between anesthesia method and the residual day- 8 PB blast cell count was examined using logistic regression analysis and inverse probability of treatment weighting (IPTW) by propensity scoring.

A cohort of 57 patients with pediatric BCP-ALL was evaluated. The residual day- 8 PB blast count was significantly lower in cases anesthetized with sevoflurane than propofol (crude odds ratio $[\mathrm{OR}]=$ 0.27 ; 95\% confidence interval $[\mathrm{CI}], 0.085-0.86 ; P=$ $0.045)$, but no difference was observed when the values were adjusted for age (adjusted $\mathrm{OR}=2.32$; 95\% CI, 0.70-7.65; $P=0.167$ ) (Table 1). Furthermore, after adjustment by the IPTW method, there was no significant difference between the two groups (adjusted $\mathrm{OR}=0.61 ; 95 \% \mathrm{CI}, 0.16-2.3 ; P=$ 0.47) (Table 2).

In this study, the number of patients with residual leukemic blast cells was significantly lower in patients receiving sevoflurane than in those receiving propofol. The reason for this result contrary to the hypothesis may be that the children in the propofol group were significantly older. Therefore, the gen-

\footnotetext{
* Correspondence: tkaneko@hyo-med.ac.jp

${ }^{1}$ Department of Anesthesiology and Pain Medicine, Hyogo College of

Medicine, Mukogawa-cho 1-1, Nishinomiya 663-8501, Japan

Full list of author information is available at the end of the article
} 
Table 1 Characteristics of patients in the study cohort that were assessed using univariate and multivariate analysis as risk factors for the presence of residual blast cells in peripheral blood on day 8 following prednisone chemotherapy

\begin{tabular}{|c|c|c|c|c|c|c|}
\hline & & & Univariate analysis & & Multivariate analysis & \\
\hline & No blasts $(n=24)$ & Residual blasts $(n=33)$ & Crude OR (95\% Cl) & $P$ value & Adjusted OR $(95 \% \mathrm{Cl})$ & $P$ value \\
\hline Age (months) & $53(37-71)$ & $74(50-148)$ & $1.01(1.00-1.02)$ & 0.074 & $1.008(0.996-1.019)$ & 0.18 \\
\hline Height (cm) & $99.2(91.2-110)$ & $125(103-149)$ & $1.04(1.01-1.07)$ & 0.013 & & \\
\hline Weight (kg) & $16.3(12.9-20.2)$ & $19.8(16-35)$ & $1.05(1.00-1.10)$ & 0.053 & & \\
\hline Gender (male) (\%) & $9(37.5)$ & $20(60.6)$ & $0.45(0.15-1.33)$ & 0.67 & & \\
\hline ASA-PS $\geqq I I I(\%)$ & $2(8.3)$ & $2(6.1)$ & $0.66(0.086-5.02)$ & 0.53 & & \\
\hline Operation time (min) & $29(23-47)$ & $27(22-30)$ & $0.97(0.93-1.01)$ & 0.15 & & \\
\hline Anesthesia time (min) & $83(73-92)$ & $83(74-92)$ & $0.99(0.97-1.01)$ & 0.45 & & \\
\hline Anesthesia method (sevoflurane) (\%) & $12(50.0)$ & $7(21.2)$ & $0.27(0.085-0.86)$ & 0.045 & $2.31(0.70-7.65)$ & 0.17 \\
\hline WBC $>50,000 / \mu \mathrm{L}$ at diagnosis (\%) & $2(8.3)$ & $8(24.2)$ & $3.23(0.619-16.9)$ & 0.18 & & \\
\hline Central nervous invasion (\%) & $1(4.2)$ & $5(15.2)$ & $3.79(0.413-34.8)$ & 0.39 & & \\
\hline Mediastinal invasion (\%) & $0(0)$ & $0(0)$ & & & & \\
\hline Hypodiploid (\%) & $1(4.2)$ & $0(0)$ & $0.393(0.284-0.554)$ & 0.40 & & \\
\hline Genetic risk (\%) & $1(4.2)$ & $6(18.2)$ & $4.714(0.528-42.10)$ & 0.22 & & \\
\hline
\end{tabular}

Data are expressed as median (25th-75th percentile) or $n$ (\%). Residual blast cells: leukemic blast cell count in peripheral blood on day 8 following prednisone chemotherapy $>0 / \mu \mathrm{L}$. Hypodiploid: fewer than 45 chromosomes. Genetic risk: Evidence of MLL-AF4, MLL reconstitution and/or E2A-HLF

$O R$ odds ratio, $\mathrm{Cl}$ confidence interval, ASA-PS American Society of Anesthesiologists physical status, WBC white blood cell count

eral anesthetics were not associated with the presence and count of residual day-8 PB blast cells after adjustment. One of the possible reasons for the lack of a relationship between anesthetics and the presence of residual day- $8 \mathrm{~PB}$ blast cells is the short duration of anesthesia (approximately $80 \mathrm{~min}$ ). Another reason is that many patients classified as the propofol group received sevoflurane at the time of procedures such as bone marrow aspiration and lumbar puncture. Use of thiopental, which has an inhibitory effect on immune cells [3], in most cases for induction of general anesthesia, might have affected the results.

This research has many limitations. First, it was a retrospective study with a small number of cases, and it may have lacked statistical power or involved confounding factors that could not be adjusted. Second, although recurrence and survival rates are considered more important outcomes, alternative endpoints were used in this study.

The results of the present study have demonstrated no superiority of sevoflurane and propofol.

Table 2 Relationship between the anesthesia method and the presence of residual blast cells in peripheral blood by inverse probability of treatment weighting (IPTW) using propensity score

\begin{tabular}{llllll}
\hline & Before weighting & & & After weighting & \\
& Group S $(n=19)$ & Group P $(n=38)$ & Crude OR (95\% Cl) & $P$ value & Adjusted OR (95\% Cl) $\quad P$ value \\
Residual blasts & $7(36.8)$ & $26(68.4)$ & $0.27(0.085-0.86)$ & 0.045 & $0.61(0.16-2.3)$
\end{tabular}

\begin{tabular}{|c|c|c|c|c|c|c|}
\hline & \multicolumn{3}{|c|}{ Before weighting } & \multicolumn{3}{|c|}{ After weighting } \\
\hline & Group S & Group P & $P$ value & Group S & Group P & $P$ value \\
\hline Blast count $(/ \mu \mathrm{L})$ & $0(0-30.0)$ & $31.5(0-349)$ & 0.014 & $1.00(0-72.0)$ & $33.4(0-314)$ & 0.20 \\
\hline
\end{tabular}

Data are expressed as $n$ (\%) or median (25th-75th percentile). Group S patients received general anesthesia with sevoflurane and group $\mathrm{P}$ received propofol. Residual blasts: number of patients in whom leukemic blast counts in peripheral blood on day 8 following prednisone chemotherapy were $>0 / \mu \mathrm{L}$. Blast count: leukemic blast cell count in peripheral blood on day 8 following prednisone chemotherapy $O R$ odds ratio, $\mathrm{Cl}$ confidence interval 


\section{Abbreviations}

BCP-ALL: Precursor B cell acute lymphocytic leukemia; Cl: Confidence interval; IPTW: Inverse probability of treatment weighting; OR: Odds ratio;

PB: Peripheral blood; tCVC: Tunneled central venous catheter

\section{Acknowledgements}

We are grateful to Tsuneo Tatara for helpful discussions and comments on the manuscript.

\section{Authors' contributions}

The authors made the following substantial contributions to this study: study design-TaK and TeK; data collection-TaK and EU; statistical analysis-TaK; data interpretation-TaK, TeK, and MH; manuscript preparation-TaK, TeK, and $\mathrm{MH}$; literature search-TaK, TeK, and EU; and revising the manuscript for intellectual content-TaK, TeK, EU, and MH. Final approval of the version to be published was given by all authors.

\section{Funding}

None.

\section{Availability of data and materials}

The datasets used and/or analyzed during the current study are available from the corresponding author on reasonable request.

\section{Ethics approval and consent to participate}

This research was approved by Hyogo Children's Hospital Ethics Committee (approval No. R30-23). The research contents were announced on the hospital website, and patient requests to withdraw from the study were accepted.

\section{Consent for publication}

Not applicable.

\section{Competing interests}

The authors declare that they have no competing interests.

\section{Author details}

'Department of Anesthesiology and Pain Medicine, Hyogo College of Medicine, Mukogawa-cho 1-1, Nishinomiya 663-8501, Japan. ${ }^{2}$ Department of Anesthesiology, Kobe Children's Hospital, Minatojima-Minamimachi 1-6-7, Chuo-ku, Kobe 650-0047, Japan.

Received: 29 July 2019 Accepted: 9 September 2019

Published online: 07 October 2019

\section{References}

1. Di N, Guo Y, Ding N. Effect of combined propofol-sevoflurane anesthesia on immune function in pediatric patients with acute lymphoblastic leukemia. Oncol Lett. 2019;18:35-42.

2. Möricke $A$, Reiter A, Zimmermann M, Gadner H, Stanulla M, Dördelmann M, Löning L, Beier R, Ludwig W-D, Ratei R, Harbott J, Boos J, Mann G, Niggli F, Feldges A, Henze G, Welte K, Beck J-D, Klingebiel T, Niemeyer C, Zintl F, Bode U, Urban C, Wehinger H, Niethammer D, Riehm H, Schrappe M, German-Austrian-Swiss ALL-BFM Study Group. Risk-adjusted therapy of acute lymphoblastic leukemia can decrease treatment burden and improve survival: treatment results of 2169 unselected pediatric and adolescent patients enrolled in the trial ALL-BFM 95. Blood. 2008;111:4477-89.

3. Melamed R, Bar-Yosef S, Shakhar G, Shakhar K, Ben-Eliyahu S. Suppression of natural killer cell activity and promotion of tumor metastasis by ketamine, thiopental, and halothane, but not by propofol: mediating mechanisms and prophylactic measures. Anesth Analg. 2003;97:1331-9.

\section{Publisher's Note}

Springer Nature remains neutral with regard to jurisdictional claims in published maps and institutional affiliations. 